\title{
Influence of Magnetic Frequency on the Thermal Behaviour of Heat Transfer Equipment
}

\author{
Samuel Sami*
}

University of Nevada, 4505 S. Maryland Pkwy, Las Vegas, NV 89154, USA

\begin{abstract}
This paper presents a description of the mathematical model developed to predict the natural frequency of a particular refrigerant or refrigerant mixture and magnetic field frequency using the one-dimensional fluid flow conservation equations. The results show the dependence of the Nusselt number on the Reynolds number in the presence and absence of magnetic field. However, the results also provide evidence of enhanced heat transfer and heat flux under magnetic field compared to without magnetic field. In addition, the results presented in the paper clearly provide evidence that the heat transmission has been consistently enhanced when magnetic field is applied. It also appears that heat transfer enhancement is greater at higher Nusselt numbers.
\end{abstract}

Keywords: Magnetic field, heat transfer, enhancement, refrigerant mixtures.

\section{INTRODUCTION}

Study of the literature revealed, in addition to what has been reported by Sami et al. [1-19], that Kim and Hyun [4] has investigated the nucleate boiling on several commercially available enhanced and smooth tubes using working fluids R-22, R-123, R-134a, R$407 \mathrm{C}$ and $\mathrm{R}-410 \mathrm{~A}$ in water/ refrigerant geometry. Wang's work concluded that heat transfer coefficients of R-410A and R-22 are comparable. Other results have been reported on two-phase flow characteristics inside smooth tube by Wijaya and Spatz [5] using R-22 and R-410A [1-9].

To the author's knowledge, the studies reported by Sami et al. [1, 3] are the only existing studies on the boiling and condensation of alternatives refrigerants under gas/liquid injection inside internally and externally enhanced surfaces, such as double fluted tubes and air-fined tubes. As new alternatives such as R-507, R-404A, R-407B, and R-408A are considered as potential alternatives to $\mathrm{R}-502$ in air-fined heat exchangers, the current research work has been done to enhance our understanding of the fluid flow boiling and heat transfer characteristics of these new alternative refrigerants inside enhanced micro-fins surface tubing.

Furthermore, it has been reported that paramagnetic fluids when subjected to strong magnetic field and magnetic forces show some changes in the thermodynamic and thermophysical properties [8-24]. Those changes are proportional to the fluid magnetic susceptibility. In addition, a magnetic convection

*Address correspondence to this author at the University of Nevada, $4505 \mathrm{~S}$. Maryland Pkwy, Las Vegas, NV 89154, USA; Tel: 702628 7348; Fax: 760476 9257; E-mail: dr.samuelsami@icloud.com develops due to the temperature variation of the magnetic susceptibility. Thermal measurements of heat transfer inside a cavity show that the magnetic force enhances the fluid flow $[12,13]$. Furthermore, Wang et al. [10] also showed that a magnetization force by an inhomogeneous magnetic field is a body force that acts on both paramagnetic and diamagnetic fluids. Wang's work also numerically investigated the magnetic effect on natural convection in non-and low conducting diamagnetic fluids focusing on the effects of the direction of the magnetic force and Rayleigh and Prant numbers.

It was also shown by Qi et al. [16] that magnetization force caused by a magnetic field gradient is a body force that can cause buoyancy. Qi et al. numerically simulated the natural convection arising from the depletion of protein concentration around protein crystal. Their numerical predictions reveal that an upward magnetization force can damp convection. Their recent experiment also demonstrated that the magnetic field force can enhance or suppress convection in a paramagnetic aqueous solution heated from either below and above.

The resonance of natural convection in a side heated enclosure with mechanically oscillating bottom wall has been studied by Kim et al. [20]. Kim studied the effect of sinusoidal time varying temperature oscillation of the hot and cold walls in natural convection and he showed the amplitude of heat transfer in the tall vertical enclosure.

On the resonance of natural frequency by an external thermal force, Lage and Bejan [22] and Sang et al. [23] performed theoretical and studies and reported the presence of resonance and its estimation. 


\section{Analytical Model}

In order to predict the effect of magnetic field on the fluid thermal behaviour, the following conservation equations have been employed;

$$
\begin{aligned}
& \partial m / \partial t=\rho V d A=m(i)-m(i+1) \\
& \rho V \partial h / \partial t+\rho h \partial V / \partial t+h V \partial \rho / \partial t-V \partial \rho / \\
& \partial t=d E / \partial t=m(i) h(i)-m(i+1) h(i+1) \\
& \partial m / \partial t V=p(i+1)-p(i)=-\tau w . s / \\
& A . \Delta x-\rho . g \cdot \cos \eta \cdot \Delta x-F l-F m-(\partial m(i) / \partial t) . \Delta x / A
\end{aligned}
$$

Where; FI and Fm are the magnetization force and Lorentz forces acting on a unit volume. And p.g represents the gravity force.;

$$
F m=\mu \cdot \chi . \nabla H . H / 2 \text { and } F l=\mu . \mu . \sigma . H . H
$$

The one dimensional fluid flow conservation equations [equations (1) through (4)] have been written using the finite difference formulation, and spatially discretized by defining the control volumes along the cross section of the pipe at full liquid condition.

The discretized governing equations have been rearranged and integrated with the equation of state to obtain the following forms;

$$
\begin{aligned}
& a . \rho(i+1)+m(i+1)-k 1=0 \\
& b . h(i+1)-a \cdot P(i+1)+k 2=0 \\
& P(i+1)+c . \rho(i+1)+d \cdot m(i+1)+k 3=0 \\
& -\rho(i+1)+e \cdot P(i+1)+f \cdot h(i+1)+k 4=0
\end{aligned}
$$

Equations (4) through (8) have been solved numerically at each control volume to determine the thermodynamic and thermophysical properties with properties; pressure, density, enthalpy and mass flow rate as independent parameters under magnetic field effects along the test cross section. The aforementioned independents parameters are spatial variables.

The pioneering work of Lage and Bejan [22] discussed by Kwak [23] was employed to determine the natural frequency of the fundamental model;

$$
f=\chi \cdot \sqrt{2} \sqrt{R a \cdot \operatorname{Pr} . \partial \theta / \partial y \cdot H) /}(H . H .4 \Pi)
$$

In order to assess the $\partial \theta / \partial y$ Kwak [23] approach was implemented at various $\mathrm{Pr}$ and Ra numbers.
Furthermore, to determine the frequency imposed by the magnetic field on the fluid flow, the following wave equation for the magnetic field is considered;

$\partial^{2} H y / \partial^{2} z=\mu_{o} \varepsilon_{o} \partial^{2} H y / \partial t^{2}$

From the above equation, we further identify the propagation velocity;

$v=1 / \sqrt{\mu_{o} \cdot \varepsilon_{o}}$

Where, equation (11) designates $\mu$ and as properties in the vacuum.

When magnetic field travels through a free space, the wave number and wave length are;

$k_{o}=\omega / c$ and $\lambda=2 \pi / k_{o}$

Where; $\omega$ and $c$ are the frequency and speed of light, respectively.

The wave length is the distance required to affect a phase change of $2 \pi$ radians which leads to the fundamental definition of the wavelength;

$\lambda=2 \pi / \beta$

$\& \beta=\omega \cdot \sqrt{\mu_{o} \cdot \varepsilon_{o} \cdot \varepsilon_{r}}$ and the intrinsic impedance is;

$\eta=\sqrt{\mu 1 / \varepsilon}$

The heat transfer forced convective coefficients can be obtained using the well known Dittos-Boelter correlation;

$\mathrm{Nu}=0.023 \operatorname{Re}^{0.80} \operatorname{Pr}^{\mathrm{n}}$

Where; $\mathrm{n}$ is an experimental constant that depends upon the working fluid properties and the nature of the convective process.

\section{RESULTS AND DISCUSSION}

We have presented a description of the mathematical model developed to predict the natural frequency of a particular refrigerant or refrigerant mixture and the magnetic field frequency using the one-dimensional fluid flow conservation equations \{Equations (1) through (13)\}. These equations have been written using the finite difference formulation and spatially discretized by using the lumped-control volume approach based upon node and link 
representation, and defining the control volumes along the heat transfer tube length before a heat exchanger. The discretized governing differential equations have been resolved for each control volume using the Runge de kutta Fehlberg with "fifth degree for the pressure and enthalpy as independent variables. In our opinion, this numerical method is more stable and suitable to solving the model in question than the fourth degree employed by Runge-Kutta used by Kuehl and Goldschmidt [14]. In fact, Kuehl and Goldschmit reported certain numerical difficulties during convergence with their method. The time steps used in this numerical scheme were in the order of $0.005 \mathrm{sec}$. The degree of convergence was estimated to be $1 \times 10^{-5}$.

In order to complete the numerical solution, the thermodynamic as well as the thermophysical properties and transport properties should be known. The mixing rules suggested by McLinden et al. [21] as well as the REFPROP version 9.1 were employed.

The default tolerance on the numerical integration results has been set to $\pm 2 \%$. This tolerance was used if no other tolerances are set in the numerical integration. This is a standard tolerance employed by many professional scientists and engineers, and also ensures that the answer is correct to three significant figures.

In the present study, values are of the heat transfer coefficient in non dimensional numbers were estimated for internal pipe flow of pure refrigerants such as R22 and refrigerant mixtures such as R407C. R407C is a zeotropic hydrofluorocarbon blend of R-32, R-125, and $\mathrm{R}-134 \mathrm{a}$ at $23 \%, 25 \%, 52 \%$. R- $410 \mathrm{~A}$ is a near-azeotropic blend of R-32 and R-125; $50 \%, 50 \%$. Boundary conditions were simulated at temperatures varying from $15{ }^{\circ} \mathrm{C}$ to $120{ }^{\circ} \mathrm{C}$ under sub cooled liquid state and magnetic flux density of $10 \mathrm{e} 4 \mathrm{wb} / \mathrm{m}^{2}$ using clusters of various permanent magnets mounted on the outside of the pipe wall. The numerical simulation was performed under initial conditions of $15^{\circ} \mathrm{C}, 0.8 \mathrm{MPa}$ and 0.03 $\mathrm{kg} / \mathrm{sec}$. Furthermore, the temperature was varied from $15^{\circ} \mathrm{C}$ to $120^{\circ} \mathrm{C}$ under sub cooled liquid state, pressure was also varied from $0.8 \mathrm{MPa}$ to $4.5 \mathrm{MPa}$ and finally mass flow rate varied from 0.03 to $0.12 \mathrm{~kg} / \mathrm{sec}$.

Figure 1 shows the Nusselt number variation at the various refrigerant temperatures from from $15{ }^{\circ} \mathrm{C}$ to $120{ }^{\circ} \mathrm{C}$ under sub cooled liquid state. The results clearly display the impact of the magnetic field on the Nusselt number. The Nusselt number is the ratio of convective to conductive heat transfer across the boundary [25]. The Nusselt number is generally a function of the Reynolds number and Prandtl number. The Dittus-Boelter correlation has been used to calculate the Nusselt number with the numerical constant " $n$ " is assumed as 0.40 for the application in question. The figure clearly shows the increased Nusselt number and the increased heat transfer rate with use of magnetic field. This represents the convective conductance between the inner surface tube and the working fluid under the application of the magnetic field.

Figure 2 depicts the frequency behaviour at various Nusselt numbers. The data in the figure points to the presence and evidence of resonance. The resonance can be identified by the maximum amplification of the fluctuation of the Nusselt numbers at a certain specific frequency. This is evident at Nu number of 12.47 where resonance was observed. This is referred to as the resonance frequency as per Lage and Bejan [22]. Furthermore, this figure also displays the natural frequency of refrigerants in question as a function of the Nusselt number. The Nusselt number is calculated with and without the magnetic field. The results also show that the resonance is nearly a linear-function of the applied heat flux when magnetic field applied to the flow.

As previously discussed the Nusselt number is the ratio of convective to conductive heat transfer across the boundary. As the numerical simulation was conducted at various mass flow rates, Figure $\mathbf{3}$ has been constructed with and without influence of the magnetic field. The convective-heat transfer coefficient values used to calculate the Nusselt number representing the heat transfer to a fluid flowing in a conduit are represented as per Figure 3 at various Reynolds numbers. The numerical value of the heat transfer coefficient as depicted in Figure $\mathbf{1}$ as a function of Nu number depends upon the reference temperature of the fluid under investigation and its thermophysical properties. The aforementioned parameters impact the Reynolds number presented in Figure 3. As shown in this figure, for a given fluid, the Nusselt number depends primarily on the flow conditions, which can be characterized by the Reynolds number with and without influence of the magnetic field.

On the other hand, Figure 2 shows the dependency of the Nusselt number on the frequency of oscillation of the working fluid. It is also important to note that the maximum gain of heat transfer occurs at a moderate frequency in a band near the resonance frequency as 


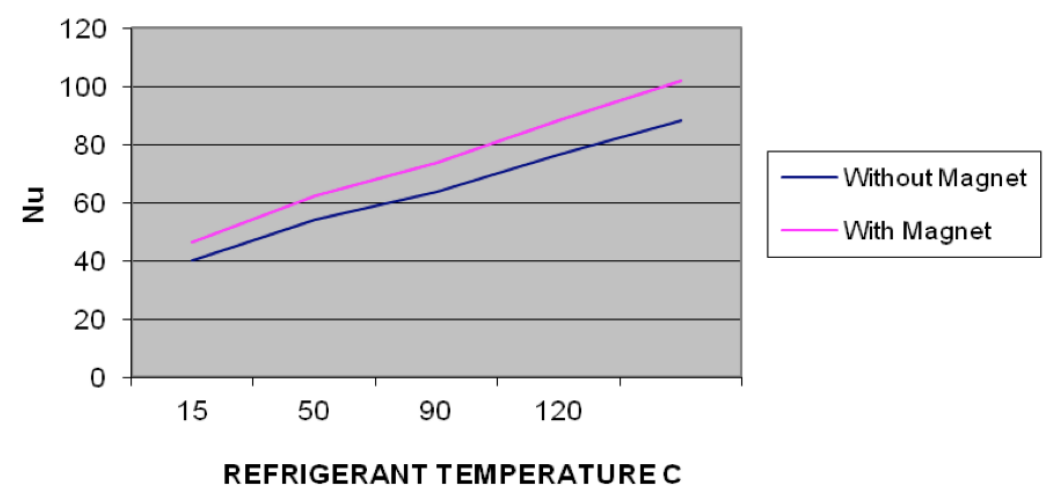

Figure 1: Impact of magnetic field on Nusselt number.

\section{Frequency v. Nu}

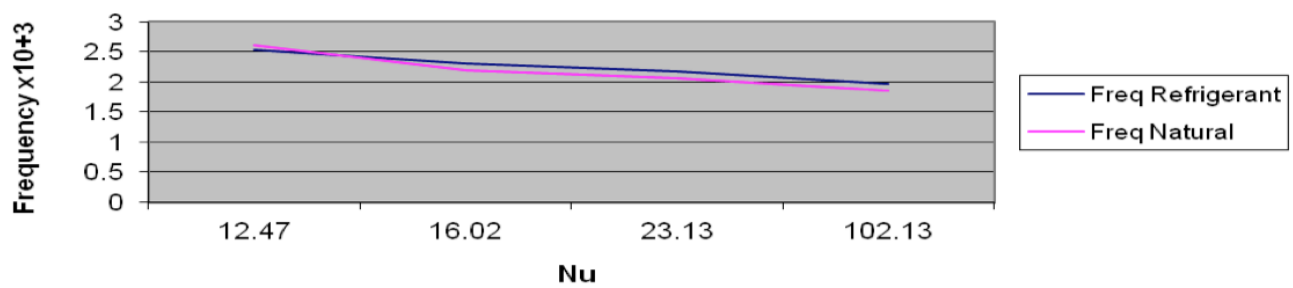

Figure 2: Frequency behaviour at various Nusselt number.

Re v. Nu

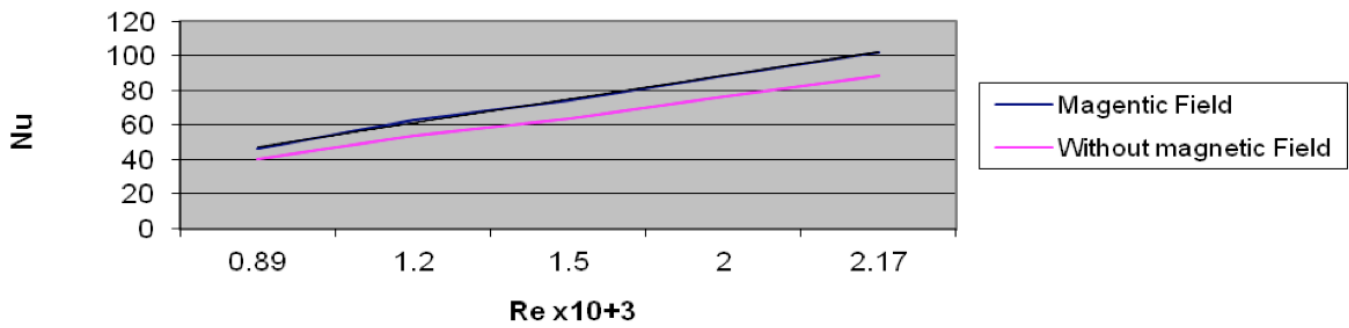

Figure 3: Nusselt number vs. Reynolds number.

shown in Figure 2. The results in Figures 2 and $\mathbf{3}$ support the assertion that the maximum gain in heat transfer is observed at a moderate frequency which is interpreted as the resonance frequency condition at 2.5 $\mathrm{x} 10^{3} \mathrm{~Hz}$.

The data presented in Figure 3 also show the dependence of the Nusselt number on the Reynolds number in the presence and absence of a magnetic field. However, it is quite important to point out that the results also show that the heat transfer and heat flux were enhanced with the presence of the magnetic field compared to the absence of the magnetic field condition.

In most engineering application, it is most convenient to present heat transfer data as a function of Nu number to illustrate the functional dependence of the heat transfer coefficient on other flow parameters. Therefore, Figure $\mathbf{4}$ has been constructed to illustrate this dependence.

The Prandtl number is a function of the fluid properties and is defined as the ratio of the kinematic viscosity of the fluid to the thermal diffusivity of the fluid [25]. It is well known that the thermal diffusivity is the measure of the ratio of the heat transmission and energy storage capacities of the molecules of the fluid [25]. It is worthwhile pointing out that the Prandtl relates the temperature distribution to the velocity distribution. Therefore, the results depicted in Figure $\mathbf{4}$ are representative of the heat transfer to the fluid under various conditions at various Nusselt numbers. 
$\mathrm{Nu} v \operatorname{Re} \mathrm{Pr}$

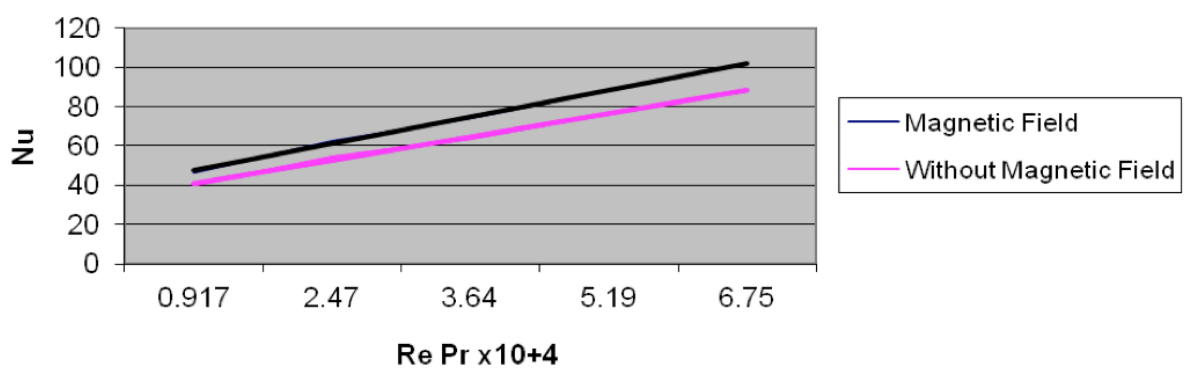

Figure 4: Effect of Prandtl number.

The data in this figure also shows that at a given Reynolds number, fluids with larger Prandtl numbers have a larger Nusselt numbers. This observation also applies to fluid exposed to magnetic field as shown in Figure 4. In addition, the results presented in the figure clearly provide evidence that the heat transmission has been consistently enhanced when magnetic field is applied compared to conditions where the magnetic field is absence. It also appears that the enhancement is greater at higher Nusselt numbers.

Furthermore, the results presented in Figures 1 to 4 also show the importance of the temperature variation on the refrigerant frequency where fluid temperature impacts the thermophysical properties and the heat transfer mechanisms (i.e. $\mathrm{Nu}, \mathrm{Pr}$ and $\mathrm{Re}$ ) as presented in Figure 5. This issue warrants further detailed investigation, however, it is beyond the scope of this study.

Figure 5 has been constructed to demonstrate the effect of working fluid temperature on its frequency oscillations. The data shows that higher oscillations occur at lower temperature and higher temperatures appeared to be associated with calmer flow i.e. low oscillation. Normally, it has been observed that the

\section{Refrigerant Frequency vs temperature}

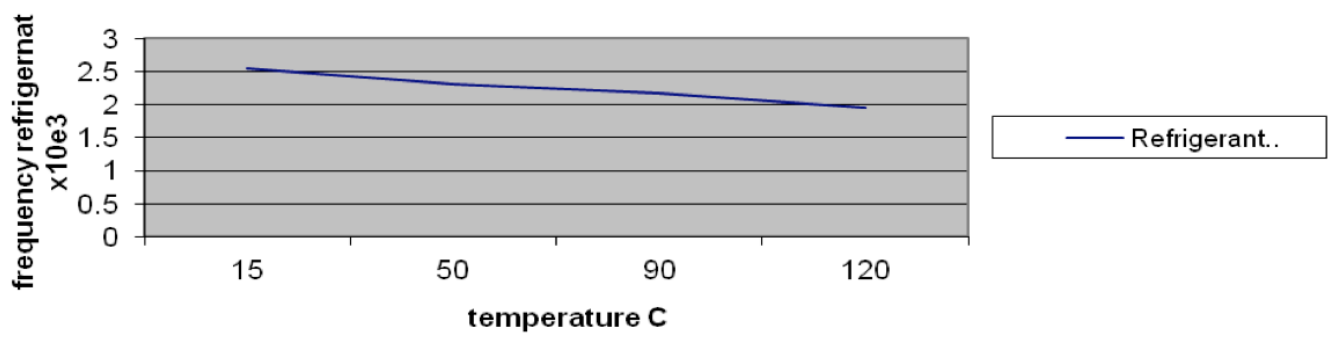

Figure 5: Effect of temperature on refrigerant frequency.

\section{Re Pr for Refrigerants}

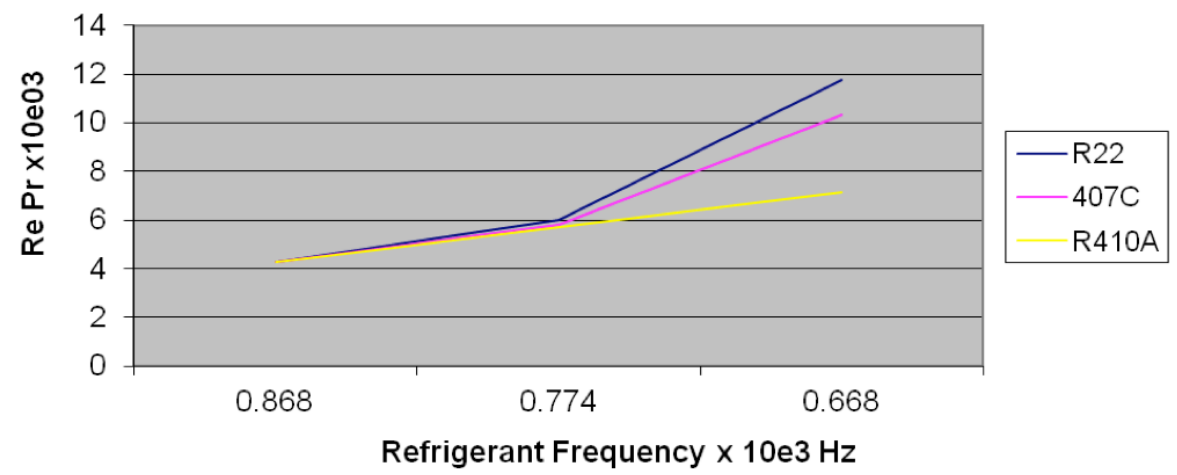

Figure 6: Effect of Re Pr numbers. 


\section{Graetz Vs Nu}

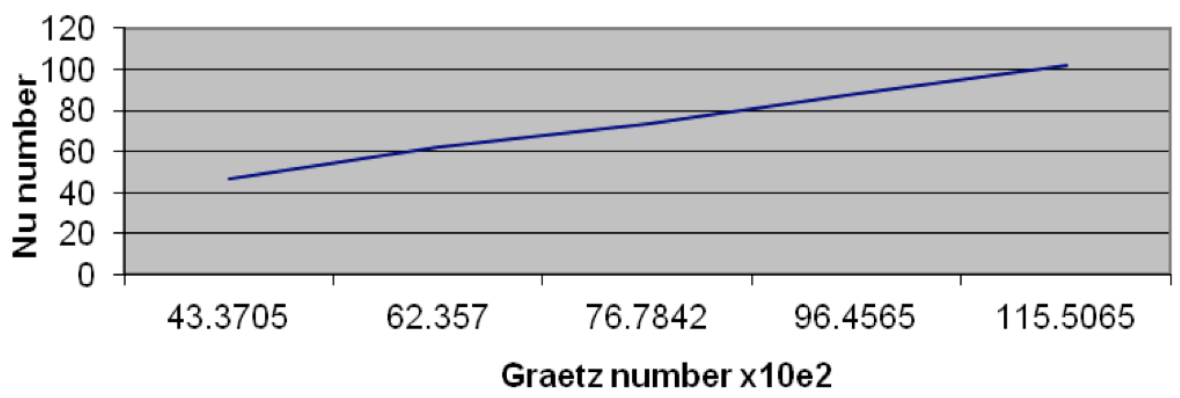

Figure 7: Effect of Graetz number.

higher the temperature the faster the liquid boils and the less violent the flow.

Pursuant to the phenomena observed in Figures $\mathbf{5}$, 6 was constructed to illustrate the heat transfer impact on the flow oscillation frequency. It is quite clear the data presented in Figures $\mathbf{5}$ and $\mathbf{6}$ are consistent for the refrigerant $R 22, R 407 c$ and $R 410 a$. It also appears that R22 and R407c exhibit the same characteristics and $\mathrm{R} 410 \mathrm{~A}$ does not perform as well as the former two refrigerants. This is due to the thermodynamic and thermophysical properties of the components R125 and R32 which have low boiling points compared to the components of R22 and R407c.

The mean Nusselt number of the flow in tubes at a uniform wall temperature and heat flux has been calculated analytically by various investigators. This has been shown to vary linearly with the Graetz number, Gz. The abscissa is the dimensional quantity $\operatorname{Re} \operatorname{Pr} D / L$. It is usually called the Graetz number that represents the conditions which correspond to the physical conditions [26]. The Graetz number depends on the nature of the fluid, and geometry of the heat exchanger. Figure 7 has been constructed to show the dependence of the Nu number on the Gratez number under magnetic field.

As can be noticed from this figure, for a high Prantl number and Graetz number, the rate of heat transfer is accelerated as the Nusselt number increases. This effect has been demonstrated by Kays [24] in circular tubes flow without the effect of magnetic field.

\section{CONCLUSIONS}

The results presented in this paper provide evidence on the enhancement of the heat transfer and heat flux under a magnetic field compared to without a magnetic field. In addition, the results presented in the figures clearly provide evidence that the heat transmission has been consistently enhanced when a magnetic field is applied. It also appears that the enhancement is greater at higher Nusselt numbers.

\section{NOMONCLATURES}
$A=$ cross sectional area
$\mathrm{D}=$ pipe diameter
$\mathrm{E}=$ Total energy
$\mathrm{g}=$ gravitational acceleration
$\mathrm{Gz}=$ Graetz number: $\operatorname{Re} \operatorname{Pr} \mathrm{D} / \mathrm{L}$
$\mathrm{h}=$ enthalpy
$\mathrm{h}_{\mathrm{c}}=$ heat transfer coefficient
$\mathrm{H}=$ magnetic field strength
$\mathrm{i}=$ node number
$\mathrm{k}_{\mathrm{f}} \quad=$ fluid thermal conductivity
$\mathrm{L} \quad=$ pipe length
$1=$ characteristic length
$\mathrm{m}=$ mass
$\mathrm{Nu}=$ Nusselt number: $\mathrm{h}_{\mathrm{c}} \mathrm{l} / \mathrm{k}_{\mathrm{f}}$
$\mathrm{p}=$ pressure
$\operatorname{Pr}=$ Prandlt number: $\mathrm{cp} \mu / \mathrm{k}$
$\mathrm{Ra}=$ Rayleigh number
$\operatorname{Re}=$ Reynolds number: $\mathrm{u} \rho \mathrm{L} / \mu$ 


$$
\begin{aligned}
\mathrm{T} & =\text { temperature } \\
\mathrm{t} & =\text { time } \\
\mathrm{u} & =\text { velocity } \\
\mathrm{V} & =\text { volume } \\
\mathrm{x} & =\text { horizontal coordinate } \\
\mathrm{z} & =\text { special distance }
\end{aligned}
$$

\section{Greek Symbols}

$=$ non-dimensional wall temperature

$\rho=$ density

$\eta=$ inclination angle

$\mathrm{T}=$ shear stress

$\mu 1=$ permeability vacuum

$\mu \quad=\quad$ Fluid viscosity

$\sigma \quad=\quad$ electric conductivity

$=\quad$ kinematic viscosity

$X=$ thermal diffusivity

\section{REFERENCES}

[1] Sami SM, Comeau J. Two phase flow convective condensation of cefrigerant mixtures under gas/liquid injection. Int J Energy Res 2005; 29.

[2] Sami SM, Comeau J. Influence of gas/liquid injection on two phase flow convective boiling of refrigerant mixtures. Int $\mathrm{J}$ Energy Res 2004; 28: 847. http://dx.doi.org/10.1002/er.1000

[3] Sami SM, Comeau J. Modelling of two phase flow pressure drop of refrigerant mixtures under liquid/gas injection conditions. Int Comm Heat Mass Transfer 2004; 31(7): 939. http://dx.doi.org/10.1016/j. icheatmasstransfer.2004.05.004

[4] Kim KH, Hyun JM. Buoyant convection in cubical enclosure under time-periodic magnetizing force. Int $\mathrm{J}$ Heat Mass Transfer 2004; 47: 5211. http://dx.doi.org/10.1016/j.ijheatmasstransfer.2004.06.015

[5] Sami SM, Comeau J. Impact of liquid injection on pressure drop of refrigerant mixtures inside enhanced surface tubing. Int Comm Heat Mass Transfer 2003; 30(8): 1091. http://dx.doi.org/10.1016/S0735-1933(03)00175-1

[6] Sami SM, Aucoin S. Behaviour of refrigerant mixtures with gas/liquid injection. Int J Energy Res 2003; 27(2): 1265. http://dx.doi.org/10.1002/er.941

[7] Sami SM, Aucoin S. Study of liquid injection impact on the performance of new refrigerant mixtures. Int $\mathrm{J}$ Energy Res 2003; 27(2); 121. http://dx.doi.org/10.1002/er.862
[8] Sami SM, Aucoin S. Effect of magnetic field on the performance of new refrigerant mixtures. Int $\mathrm{J}$ Energy Res 2003; 27(3): 203. http://dx.doi.org/10.1002/er.868

[9] Sami SM, Comeau J. Study of viscosity and thermal conductivity effects on condensation characteristics of some new alternative refrigerant mixture. Int $\mathrm{J}$ Energy Res 2003; 27: 63.

http://dx.doi.org/10.1002/er.859

[10] Wang LB, Nobuko, Wakaanna NI. Control of natural convection in non- and low conducting diamagnetic fluids in a cubical enclosure using inhomogeneous Magnetic Fields with different Directions. Chem Eng Sci 2002; 57: 1867-1876. http://dx.doi.org/10.1016/S0009-2509(02)00090-8

Sami SM, Comeau J. Influence of thermophysical properties on two phase flow convective boiling of refrigerant mixtures. J Appl Thermal Eng 2002; 22: 1535. http://dx.doi.org/10.1016/S1359-4311(02)00089-3

[12] Kim SK, Kim SY, Choi YD. Resonance of natural convection in a side heated enclosure with mechanically oscillating bottom wall. Int J Heat Mass Transfer 2002; 45: 3155.

http://dx.doi.org/10.1016/S0017-9310(02)00030-3

[13] Khaldi F, Gillon P. Étude Éxperimentale et numérique de la convention theromagnétique dans un fluide non électroconducteur. C.R. Acd Sci t. 2001; 329: Série II b, p. 357-362.

[14] Sami SM, Desjardins D, Maltais H. Prediction of capillary tubes with alternative refrigerants to CFC-502. Int J Energy Res 2001; 25: 1249. http://dx.doi.org/10.1002/er.751

[15] Sami SM, Maltais H. Experimental analysis of capillary tubes behaviour with some HCFC-22 alternative refrigerants to HCFC-22. Int J Energy Res 2001; 25: 1233.

http://dx.doi.org/10.1002/er.750

[16] Qi J, Wakayanna NI, Ataka M. Magnetic suppression of convection in protein crystal growth processes. J Crystal Growth 2001; 232: 132-137. http://dx.doi.org/10.1016/S0022-0248(01)01147-2

[17] Sami SM, Desjardins D. Boiling characteristics of ternary mixtures inside enhanced surface tubing. Int Comm Heat Mass Transfer J 2000; 27(8): 1047. http://dx.doi.org/10.1016/S0735-1933(00)00192-5

[18] Sami SM, Desjardins D. Heat transfer of ternary mixtures inside enhanced Surface Tubing. Int Comm Heat Mass Transfer J 2000; 27(6): 855 http://dx.doi.org/10.1016/S0735-1933(00)00166-4

[19] Sami SM, Desjardins D. Performance comparative study of new alternatives to R 502 inside air/refrigerant enhanced surface tubing. Int J Energy Res 2000; 24: 177. http://dx.doi.org/10.1002/(SICl)1099114X(200002)24:2<177::AID-ER580>3.0.CO;2-A

[20] Kim HS, Kuwwashara K, Hyun JM. Prediction of the resonance frequency of natural convection in an enclosure with time-periodic heating imposed side wall. J Heat Mass Transfer 1998; 41: 3157. http://dx.doi.org/10.1016/S0017-9310(98)00019-2

[21] McLinden MO. NIST Thermodynamic properties of refrigerant and refrigerant mixtures data base. 1998; Version 6.01, NIST, Gaithersburg, ND.

[22] Lage JL, Bejan A. The Resonance of natural convection in a enclosure heated periodically from inside. J Heat Mass Transfer 1993; 36: 2027. http://dx.doi.org/10.1016/S0017-9310(05)80134-6

[23] Sang Kwak HS, Kuwahara K, Hyun JM. Prediction of the resonance frequency of natural convection in an Enclosure with-periodic heated imposed on one sidewall. J Heat Mass Transfer 1998; 41: 3157. http://dx.doi.org/10.1016/S0017-9310(98)00019-2 
[24] Kays WH. Numerical solutions for laminar flow heat transfer in circular tubes. Trans, ASME 1955; Vol. 77.

[25] Cengel, Yunus A, Ghajar, Afshin J. Heat and mass transfer: Fundamentals and Applications McGraw-Hill 2010; 4th Edition.

Received on 10-06-2014

Accepted on 15-09-2014
Nellis G, Klein S. Heat transfer (Cambridge), 2009; p. 663.

DOI: http://dx.doi.org/10.6000/1929-6002.2014.03.04.4 